\title{
A win-win solution?: A critical analysis of tiered pricing to improve access to medicines in developing countries
}

\author{
Suerie Moon ${ }^{1 *}$, Elodie Jambert ${ }^{2}$, Michelle Childs ${ }^{2}$ and Tido von Schoen-Angerer ${ }^{2}$
}

\begin{abstract}
Background: Tiered pricing - the concept of selling drugs and vaccines in developing countries at prices systematically lower than in industrialized countries - has received widespread support from industry, policymakers, civil society, and academics as a way to improve access to medicines for the poor. We carried out case studies based on a review of international drug price developments for antiretrovirals, artemisinin combination therapies, drug-resistant tuberculosis medicines, liposomal amphotericin B (for visceral leishmaniasis), and pneumococcal vaccines.

Discussion: We found several critical shortcomings to tiered pricing: it is inferior to competition for achieving the lowest sustainable prices; it often involves arbitrary divisions between markets and/or countries, which can lead to very high prices for middle-income markets; and it leaves a disproportionate amount of decision-making power in the hands of sellers vis-à-vis consumers. In many developing countries, resources are often stretched so tight that affordability can only be approached by selling medicines at or near the cost of production. Policies that "de-link" the financing of R\&D from the price of medicines merit further attention, since they can reward innovation while exploiting robust competition in production to generate the lowest sustainable prices. However, in special cases such as when market volumes are very small or multi-source production capacity is lacking - tiered pricing may offer the only practical option to meet short-term needs for access to a product. In such cases, steps should be taken to ensure affordability and availability in the longer-term.
\end{abstract}

Summary: To ensure access to medicines for populations in need, alternate strategies should be explored that harness the power of competition, avoid arbitrary market segmentation, and/or recognize government responsibilities. Competition should generally be the default option for achieving affordability, as it has proven superior to tiered pricing for reliably achieving the lowest sustainable prices.

Keywords: Essential Medicines, Tiered Pricing, Differential Pricing, Access to Medicines, Developing Countries, Lowand Middle-income countries (LMIC), Drugs, Pharmaceuticals, Market segmentation

\section{Background}

"Access to drugs cannot depend on the decisions of private companies

but is also a government responsibility."

- WHO Commission on Intellectual Property Rights, Innovation and Public Health (WHO 2006)

\footnotetext{
* Correspondence: suerie_moon@hksphd.harvard.edu

'Harvard Kennedy School and School of Public Health, Boston, USA

Full list of author information is available at the end of the article
}

The concept of selling essential medicines (drugs and vaccines) in low- and middle-income countries (LMICs) [1] at prices systematically lower than those in industrialized countries-a practice known as tiered pricing-has received widespread support from industry, policymakers, civil society, and academics as a way to improve access to these life-saving products. International tiered pricing has been proposed as an alternative to high prices when separable high- and low-to-middle-income markets exist for a medicine and when the seller exerts significant power over pricing, such as when there is

\section{Biomed Central}

(c) 2011 Moon et al; licensee BioMed Central Ltd. This is an Open Access article distributed under the terms of the Creative Commons Attribution License (http://creativecommons.org/licenses/by/2.0), which permits unrestricted use, distribution, and reproduction in any medium, provided the original work is properly cited. 
limited or no competition due to patent protection, data exclusivity, or other market-entry barriers [2].

Medicines are being patented more widely in developing countries with the implementation of the World Trade Organization Agreement on Trade Related Aspects of Intellectual Property Rights (TRIPS). At the same time, the pharmaceutical market and industry is increasingly globalizing, competitive pharmaceutical producers in LMICs are emerging, unmet health needs in the developing world remain immense, and political demand for access to new products offering significant therapeutic advance is likely to grow [3]. Against this background, assessing if and how tiered pricing supports globally equitable access to medicines is critical.

Although "still very much in its infancy [4], " tiered pricing has attracted increased attention both in the pharmaceutical sector and among public actors [5-8]. The business case for tiered pricing is strong: when markets can be separated, adapting the product price to the consumer's willingness or ability to pay is a profitmaximizing strategy. At the same time, adopting such pricing can increase consumer welfare by bringing previously unaffordable products within reach. In short, tiered pricing of pharmaceuticals has received widespread support as a "win-win-win" approach to addressing access issues [9].

However, evidence and experience suggest that, in practice, tiered pricing has a number of significant drawbacks. Examining specific drug-pricing case studies, we offer here a critique of tiered pricing, organized around three key questions: (1) How can medicines be made affordable in LMICs? (2) Who should pay for research and development (R\&D) and how much? (3) Who decides pricing and how?

\section{Discussion}

\section{Key Concepts}

\section{Tiered pricing versus equity pricing}

Various terms are often used synonymously with, or are related to, tiered pricing [8], including "differential pricing, " "market segmentation, " "price discrimination, " and less frequently "Ramsey pricing $[2,10]$." We use the term "tiered pricing" to refer to the practice of systematically setting higher prices in higher-income markets and lower prices in lower-income markets, such that there is some positive correlation between price and income. Notably, tiered pricing does not necessarily imply that a price is equitable or affordable; rather, it simply means that different prices are charged to different segments of the market for the same product.

In contrast, the concept of "equity pricing" focuses on affordability and is closely linked to the World Health Organization (WHO) concept of essential medicines, which are "intended to be available within the context of functioning health systems at all times in adequate amounts... at a price the individual and the community can afford [11]." Equity pricing emphasizes the perspective of the consumer, ie, whether a price is affordable and acceptable to him or her. In contrast, tiered pricing emphasizes the perspective of the producer, ie, whether a fair profit can be sustained while charging lower prices to lower-income populations. While tiered pricing may lead to equitable prices, the concepts are not equivalent and there is no guarantee that tiered prices are affordable.

\section{Affordability}

When is a medicine price equitable or affordable? Measuring affordability is not straightforward and depends on various factors, including the purchaser (eg, individual, household, community, private insurer, national health system, or international donor) and product specificities (eg, whether the expense is one-time or recurring).

Different approaches to measuring affordability have been proposed, including benchmarking medicine prices against per capita gross national income (GNI), setting prices against "catastrophic" household health expenditure levels [12], or converting prices to working days based on government salaries as a proxy for average income [13]. However, since these methods do not account for widely varying levels of income inequality in different countries [14], Niëns et al. developed a methodology to measure affordability based on the proportion of a population that would be pushed below a poverty line (either $\$ 1.25$ or $\$ 2$ per capita/day) by the purchase of a medicine, ie, "the impoverishing effect of a medicine." [15] This methodology offers the advantage of comparability across time and countries using available data, while being sensitive to widely varying income distributions within countries.

Regardless of the range of possible measures of affordability, actually achieving or approaching affordability, particularly for the poorest populations, likely requires attaining the lowest sustainable price, which approaches the cost of production in a competitive market. We define "lowest sustainable price" here as one that provides sufficient profit to the producer to incentivize ongoing production.

\section{Evidence from Drug Pricing Case Studies}

We reviewed experiences with tiered pricing over the past decade across a diverse set of products, including antiretrovirals for HIV/AIDS, artemisinin-combination therapy for malaria, treatments for drug-resistant tuberculosis, drugs for visceral leishmaniasis, and the pneumococcal vaccine; we found that each case offered distinct insights regarding the relative utility of tiered pricing, as detailed in the following sections. 


\section{HIV/AIDS: Antiretrovirals}

Among different therapeutic areas, the availability of data and analysis on tiered pricing is greatest for HIV/ AIDS. In a review of over 7,000 developing-country purchase transactions from 2002-2007, Waning et al. found that the tiered prices for 15 of 18 antiretroviral (ARV) drugs were $23-498 \%$ higher than the generic price [16]. As of mid-2011, of the three products for which tiered prices were lower than generic prices, two products now have lower-cost generics available.

Similarly, an analysis of publicly announced prices found that of the 30 products for which both originator tiered prices and WHO pre-qualified generic prices were listed, the generic price was lower for 27 products (90\%) [17]. In at least one case, the generic price fell between the originator's Category 1 (roughly, lowerincome countries) and Category 2 (roughly, middleincome countries) tiered price.
Finally, medicines prices tend to fall further when more competitors enter the market [18] (Figure 1), though the optimal number of competitors for a given product market will depend on a number of factors, including market size, economies of scale in production, and regulatory measures to prevent oligopolistic or collusive pricing $[19,20]$.

Overall, the evidence from ARVs strongly suggests that generic prices are generally lower than tiered prices, and that competition among multiple producers systematically results in dynamic price reductions.

The special case of lopinavir/ritonavir The price history of the fixed-dose combination (FDC) ARV lopinavir/ritonavir $\left(\mathrm{LPV} / \mathrm{r}\right.$; Kaletra $\left.{ }^{\circledR}\right)$ merits special attention, both for its complexity and the lessons it holds regarding the potential pitfalls of tiered pricing. LPV/r is a critical drug for second-line HIV/AIDS treatment; the 2009 WHO HIV/AIDS treatment guidelines recommend

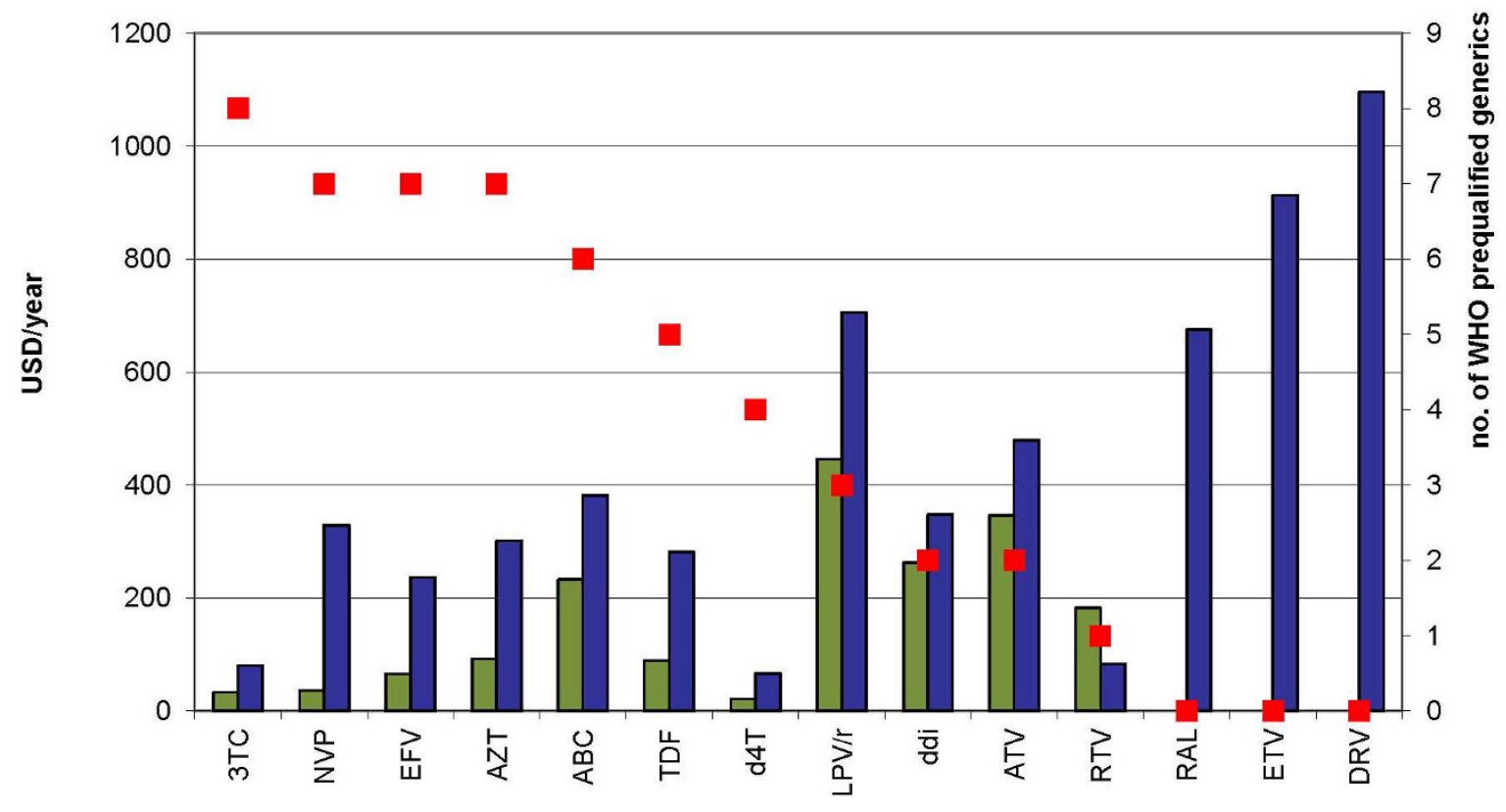

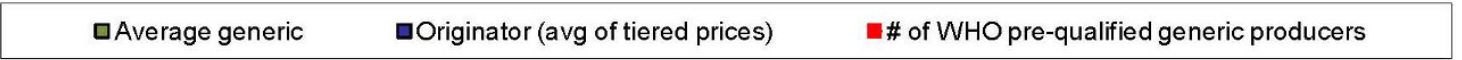

Figure 1 Number of competing WHO-prequalified suppliers by antiretroviral product. All prices are per patient/per year. $3 \mathrm{TC}=$ lamivudine 150 mg; NVP = nevirapine 200 mg; EFV = efavirenz 600 mg; AZT = zidovudine 300 mg; ABC = abacavir 300 mg; TDF = tenofovir 300 mg; d4T = stavudine 30 mg; LPV/r = lopinavir/ritonavir 200/50 mg; ddl = didanosine 400 mg enteric coated; ATV = atazanavir 150 mg; RTV = ritonavir 100 mg; RAL = raltegravir 400 mg; ETV = etravirine 100 mg; DRV = darunavir 300 mg. Source: MSF 2011 [17] 
only one other protease inhibitor (PI), atazanavir (ATV), which must be taken together with ritonavir but is not yet available as an FDC with ritonavir [21]. Since 2006, $\mathrm{LPV} / \mathrm{r}$ has been available in a heat-stable formulation that is well-suited for settings where refrigeration is scarce. LPV/r is by far the most widely used PI in developing countries, administered to $93 \%$ of adults on second-line treatment [22].

Abbott Laboratories holds the patents on lopinavir and ritonavir and initially announced a tiered price of $\$ 650$ for LPV/r in 2001 for African countries and 16 non-African least developed countries (LDCs) [23]. In 2002, Abbott announced a price drop to $\$ 500$ for all African countries and LDCs (Category 1 countries). From 2002-2009, Abbott's price for Category 1 countries did not change (Figure 2). During this period, the lowest generic price for $\mathrm{LPV} / \mathrm{r}$ remained above $\$ 500$, ie, no effective price competition existed in the market. In August 2009, the Clinton HIV/AIDS Initiative (CHAI) announced that generic LPV/r would be available at $\$ 470$, the first time the generic price fell below Abbott's tiered price. Several weeks later, for the first time in 7 years, Abbott reduced its price, dropping it to $\$ 440$, or slightly below the lowest generic price. This history suggests that producers do not have strong incentives to reduce tiered prices in the absence of competition, nor are tiered prices immune to competition when it does arise.

While Category 1 countries received the lowest global price for LPV/r for a number of years, excluded countries negotiated prices with Abbott case by case, often resulting in very high prices. For example, in 2005 the price of LPV/r offered to Médecins Sans Frontières (MSF) programs in China was $\$ 5,000$ [24], while in
2006 Honduras paid $\$ 7,775$. Under strong civil society pressure, in 2006 Abbott offered a Category 2 tiered price of $\$ 2,200$ for a group of 40 developing countries excluded from its initial offer. However, some governments considered this price too high, and after Thailand issued a compulsory license on the drug in January 2007, Abbott dropped the Category 2 price again by more than half to $\$ 1,000$. As of July 2010, the price has remained at $\$ 1,000$ for a group of 45 LMICs. The pricing of LPV/r for non-Category 1 countries illustrates the difficulty of setting equitable and affordable tiered prices across diverse country contexts.

Finally, tiered pricing may have anti-competitive effects if the price is so low that it discourages market entry by potential competitors. Abbott controlled 80$100 \%$ (by volume) of the developing-country LPV/r market from 2006 to 2008 [25]. Abbott's dominance in this market contrasts with other ARVs, in which generics supply $80 \%$ or more of the developing-country market (by volume). Questions have been raised regarding whether the company's pricing policies were intended to prevent competition [26-28]. While consumers may benefit in the short term from tiered prices set below production costs, the resultant lack of competition and absence of dynamic price reductions means that consumers may pay higher prices in the long term.

\section{Malaria: Artemisinin-based Combination Therapies}

As with ARVs, evidence from the market for artemisinin-based combination therapy (ACT) drugs for malaria shows that generic competition yields lower prices than tiered pricing alone.

In 2001, Novartis offered WHO an "at-cost" tiered price for developing countries of $\$ 2.40$ per adult treatment course for artemether-lumefantrine (AL;

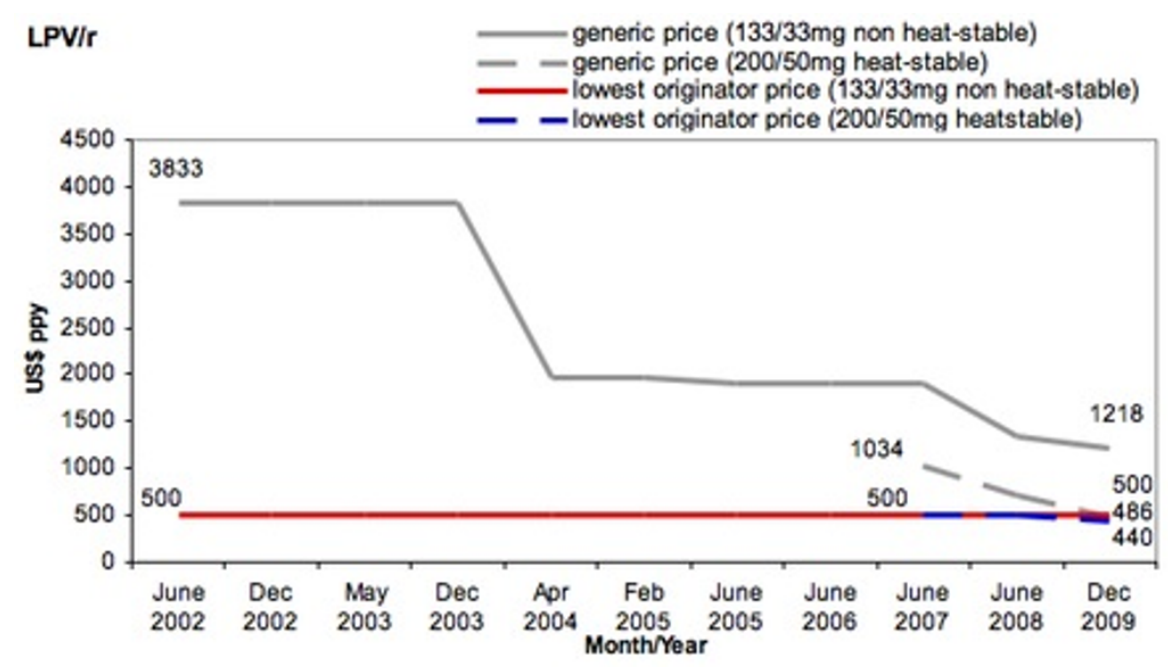

Figure 2 Lopinavir/ritonavir price trends, 2002-2009. Source: MSF 2010 [17] 
Coartem $^{\circledR}$ ) [29]. For several years, AL was the only fixed-dose combination ACT that met the quality requirements of the WHO or Global Fund to Fight AIDS, Tuberculosis and Malaria (GFATM); therefore, no competition existed in the donor-funded ACT market. The tiered price did not change for 5 years (Figure 3) [30]. After a generic version of AL became eligible for GFATM purchase, Novartis decreased its price to $\$ 1.80$, then dropped its tiered price again to $\$ 1.50$ shortly after the FDC of artesunate-amodiaquine (ASAQ), a substitute and competitor to AL in some countries, entered the market at \$1.00.

Evidence from the global ACT market suggests that competition helps reduce tiered prices, and underscores the need to ensure that "at-cost" pricing is independently verifiable and reflects changes in production costs over time.

\section{Tuberculosis: Medicines for Drug-Resistant Disease}

Most medicines for tuberculosis (TB) are widely available as low-cost generics, but some medicines for drugresistant TB (DR-TB, including multidrug-resistant and extensively drug-resistant TB) can be quite costly, and may be offered at a tiered price. Eli Lilly produced two key DR-TB drugs, capreomycin and cycloserine, which are off patent but not widely available from other suppliers. In 2002, Lilly began supplying the drugs at a "preferential price" through the WHO Green Light Committee (GLC), and transferred the technology to produce the drugs and its active pharmaceutical ingredient (API) to several generic drug companies in TBendemic countries. Unlike for ARVs or ACTs, the tiered price has consistently remained below the generic prices for these drugs.
Capreomycin: As of September 2011, no generic sources of capreomycin were WHO Pre-Qualified (PQ). In 2001, GLC-approved programmes were able to access Lilly's capreomycin for $\$ 1.02$ per vial. Since 2001, the price has increased nearly four-fold to $\$ 4.00$ per vial for the WHO Global Drug Facility [31]. A further price increase is expected in the near future, now that Lilly has stopped production for this market, and the GDF begins sourcing capreomycin from the pharmaceutical producer Akorn, which has reported a price of $\$ 8$ per vial (Table 1) [31]. While the Akorn price to the GDF is still relatively high, it is lower than the price found in industrialized countries of $\$ 40.95$ per vial [32].

Cycloserine: By 2009, after technology transfer from Lilly, two generic WHO prequalified sources of cycloserine were available. In 2001, GLC-approved programmes were able to access Lilly's cycloserine for $\$ 0.14$ per capsule, but in 2008 Lilly stopped producing the drug. The price of cycloserine has since increased by over fourfold to $\$ 0.59$ per capsule (Table 2) [31]. However this price remains considerably more affordable than prices paid in high-income countries; for example, the British National Formulary lists a price of $\$ 5.43$ per capsule [32].

This experience suggests that under special circumstances tiered pricing may result in lower prices than competitive production. When demand is low and production capacity limited, a single producer selling at tiered prices in developing countries may result in lower prices than would otherwise be feasible. Notably, the GLC has approved a cumulative total of only 49,858 patient treatments from 2000-2008 [33]. In 2009, only 30,475 of the estimated 440,000 new patients with MDR

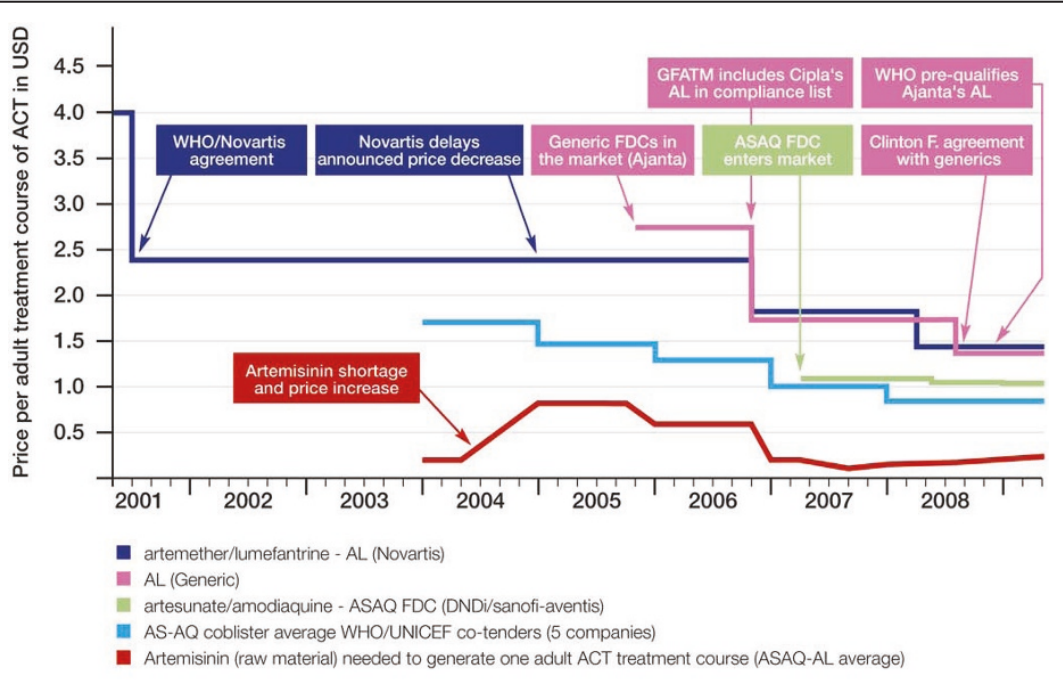

Prices exclude main carriage/freight and insurance costs

Figure 3 Artemisinin-based combination therapy drug price trends 2001-2008. Source: Moon et al. 2009 [30] 
Table 1 Capreomycin tiered prices

\begin{tabular}{llll}
\hline Manufacturers & Akorn & Mac Leods & GDF pooled procurement price \\
\hline Quality status & Approved by a Stringent Regulatory Authority & Under evaluation by WHO PQ & GDF Quality Assurance Policy \\
\hline $\mathbf{1}$ g powder for injection & 8.00 & No price information given & $\begin{array}{l}4.00^{*} \\
\text { (Eli Lilly) }\end{array}$ \\
\hline
\end{tabular}

Price and quality information. Price of the lowest unit (i.e. the price of one tablet, capsule or vial) in USD (\$)

* In future, the lowest available price is expected to change as the Akorn product replaces Eli Lilly's.

Sources: British National Formulary 2010 [32]; Global Fund 2010 [54]; Management Sciences for Health 2009 [55]; personal communication, M. Price, 2010.

TB were started on treatment [34]. While the market for DR TB drugs is growing, the patient numbers remain quite small. Generic prices may fall as global volumes increase, producers achieve economies of scale, and/or more producers of API or finished products enter the market. Nevertheless, from 2000 when Lilly began supplying capreomycin and cycloserine to the GLC, until generic suppliers were able to takeover supply (2007 for cycloserine, projected 2011 or later for capreomycin), Lilly's tiered price has likely helped to ease access problems related to the cost of DR-TB drugs.

\section{Visceral Leishmaniasis: Liposomal Amphotericin B}

Amphotericin $B$ is used to treat fungal infections, as well as visceral leishmaniasis (VL; kala azar), a fatal neglected tropical disease highly endemic in India, Bangladesh, Nepal, Sudan, Ethiopia, and Brazil. Amphotericin B is better tolerated by patients who do not respond well to sodium stibogluconate, the standard VL treatment in some countries, and is recommended for treatment of VL patients co-infected with HIV. Use of the liposomal formulation of amphotericin B (AmBisome ${ }^{\mathbb{B}}$, produced by Gilead Sciences) has significantly fewer side effects than conventional amphotericin B [35].

In 1992, Gilead agreed with WHO to supply liposomal amphotericin B (LAmB) for treatment of VL to developing countries at cost plus $10 \%$, ie, $\$ 50 /$ vial ( $\$ 700 /$ treatment) (Table 3). In 2005, an informal WHO expert consultation recommended using $\mathrm{LAmB}$ to treat $\mathrm{VL}$ and highlighted the need for wider access. The following year, Gilead and WHO agreed on a tiered price of \$20/ vial for VL and mucosal leishmaniasis in developing countries; in August 2009, Gilead reduced the price further to $\$ 18 /$ vial and committed to update the price annually depending on its production cost, with a price ceiling of $\$ 20$ (personal communication, G. Alton, 2009). In India, Cipla marketed a generic LAmB version for $\$ 140 /$ vial and offered a specially discounted price for VL treatment of $\$ 25 /$ vial. The UK private sector price in 2010 was $\$ 153 /$ vial.

The case of LAmB suggests that it is possible to segment markets by indication. However, similar discounts are also needed for use against other fungal infections such as meningococcal meningitis in people living with HIV/AIDS, illustrating the public health limits of segmenting markets by indication. With only two producers, the market for this formulation is not yet competitive; but in the medium term, if the market expands and can attract more competitors, prices for LAmB may decrease and make this drug more accessible for both patients with VL and those with other fungal infections. In the short term, the tiered prices most likely increased access to this medicine specifically for the treatment of VL.

\section{New Vaccines: Pneumococcal Vaccine}

Older vaccines have long been available at relatively low cost in developing countries. However, newer, more expensive vaccines have been recently developed, such as for rotavirus, human papillomavirus, and pneumonia, raising questions regarding access in developing countries. In 2010, controversy arose around the tiered pricing of pneumococcal vaccines.

For three decades, the Pan American Health Organization (PAHO) has procured vaccines at low prices for Latin America through its Revolving Fund; by aggregating demand across a set of small- and medium-sized countries, the Revolving Fund strengthened the negotiating leverage of governments vis-à-vis suppliers. Revolving Fund contracts include a "most favored

Table 2 Cycloserine tiered prices

\begin{tabular}{llllll}
\hline Manufacturers & Lupin & Aspen & Mac Leods & Purdue GMP & $\begin{array}{l}\text { GDF pooled } \\
\text { procurement price }\end{array}$ \\
\hline Quality status & $\begin{array}{l}\text { Under evaluation by } \\
\text { WHO PQ }\end{array}$ & $\begin{array}{l}\text { Approved by } \\
\text { WHO PQ }\end{array}$ & $\begin{array}{l}\text { Approved by WHO } \\
\text { PQ }\end{array}$ & $\begin{array}{l}\text { Approved by a Stringent Regulatory } \\
\text { Authority }\end{array}$ & $\begin{array}{l}\text { GDF Quality Assurance } \\
\text { Policy }\end{array}$ \\
\hline $\begin{array}{l}\mathbf{2 5 0} \mathbf{~ m g} \\
\text { capsule }\end{array}$ & 0.60 & 0.78 & No price information & No price information given & 0.59 and 0.78 \\
& & & given & & $\begin{array}{l}\text { (Macleods and } \\
\text { Aspen) }\end{array}$ \\
\end{tabular}

Price and quality information. Price of the lowest unit (i.e. the price of one tablet, capsule or vial) in USD (\$)

Sources: British National Formulary 2010 [32]; Global Fund 2010 [54]; Management Sciences for Health 2009 [56]; personal communication, M. Price, 2010. 
Table 3 Liposomal amphotericin B tiered prices (prices in USD (\$)

\begin{tabular}{lcccc}
\hline & \multicolumn{2}{c}{$\begin{array}{c}\text { Average unit price } \\
\text { (year)* }\end{array}$} & \multicolumn{2}{c}{$\begin{array}{c}\text { Average treatment cost } \\
\text { (year) }\end{array}$} \\
\hline Liposomal amphotericin B & Gilead & Lowest generic (Cipla VL price) & Gilead & Lowest generic (Cipla VL price) \\
\hline WHO & $18(2009)$ & $25(2008)$ & $252(2009)$ & $350(2008)$ \\
\cline { 2 - 5 } & $20(2006)$ & $280(2006)$ & $700^{\dagger}(1991)$ \\
\cline { 2 - 5 } & $50(1991)$ & $2,142(2010)$ & \\
\hline UK private market & $153(2010)$ & &
\end{tabular}

*Currency converted using http://www.oanda.com on 13 December 2010.

${ }^{\dagger}$ Based on an average weight of $35 \mathrm{~kg}$ for a patient with visceral leishmaniasis, 14 vials are required for a full treatment course.

$\mathrm{VL}=$ visceral leishmaniasis.

Sources: personal communication, G. Alton, 2009.

nation" clause that requires suppliers to give PAHO their lowest available price. However, with most Latin American countries falling into the lower-middle or upper-middle income categories, the requirement that PAHO receive the lowest global prices has clashed with producers' tiered pricing strategies, which charge higher prices to middle-income countries.

In 2008-2009, PAHO negotiated a price of $\$ 21.75$ / dose for Wyeth's pneumococcal 7-valent conjugate vaccine $\left(\right.$ Prevnar $\left.^{\mathbb{B}}\right)$. A 10-valent vaccine protecting against a broader range of serotypes was developed by GSK $\left(\right.$ Synflorix ${ }^{\circledR}$ ), which will supply it through the Advance Market Commitment (AMC) mechanism of the Global Alliance for Vaccines and Immunization (GAVI) for up to 72 developing countries [36]. The initial price is $\$ 7 /$ dose for approximately $20 \%$ of the total quantity provided, which then decreases to a "tail" price of $\$ 3.50$ / dose for the remainder [37]. PAHO could not obtain the same price from GSK and initially decided not to purchase the 10 -valent vaccine.

In parallel, the government of Brazil negotiated an 8year agreement with GSK to purchase the 10-valent vaccine initially at $\$ 16 /$ dose (Figure 4 ), decreasing to $\$ 7$ in later years; the beginning and tail prices are roughly double the GAVI price. GSK has also agreed to transfer technology to the Brazilian public manufacturer BioManguinhos to produce the vaccine by the end of the 8 -year period. The same vaccine is sold at $\$ 49-56 /$ dose in Europe and $\$ 71 /$ dose in the US [38]. The Brazil-GSK agreement may have had a price setting effect for the region as PAHO subsequently accepted a price of $\$ 14.85$ / dose. GSK furthermore succeeded in separating the GAVI and PAHO markets with two different presentations of the same vaccine (two and one dose vials respectively).

The pneumococcal vaccine case highlights several difficulties with tiered pricing. First, no mechanism is in

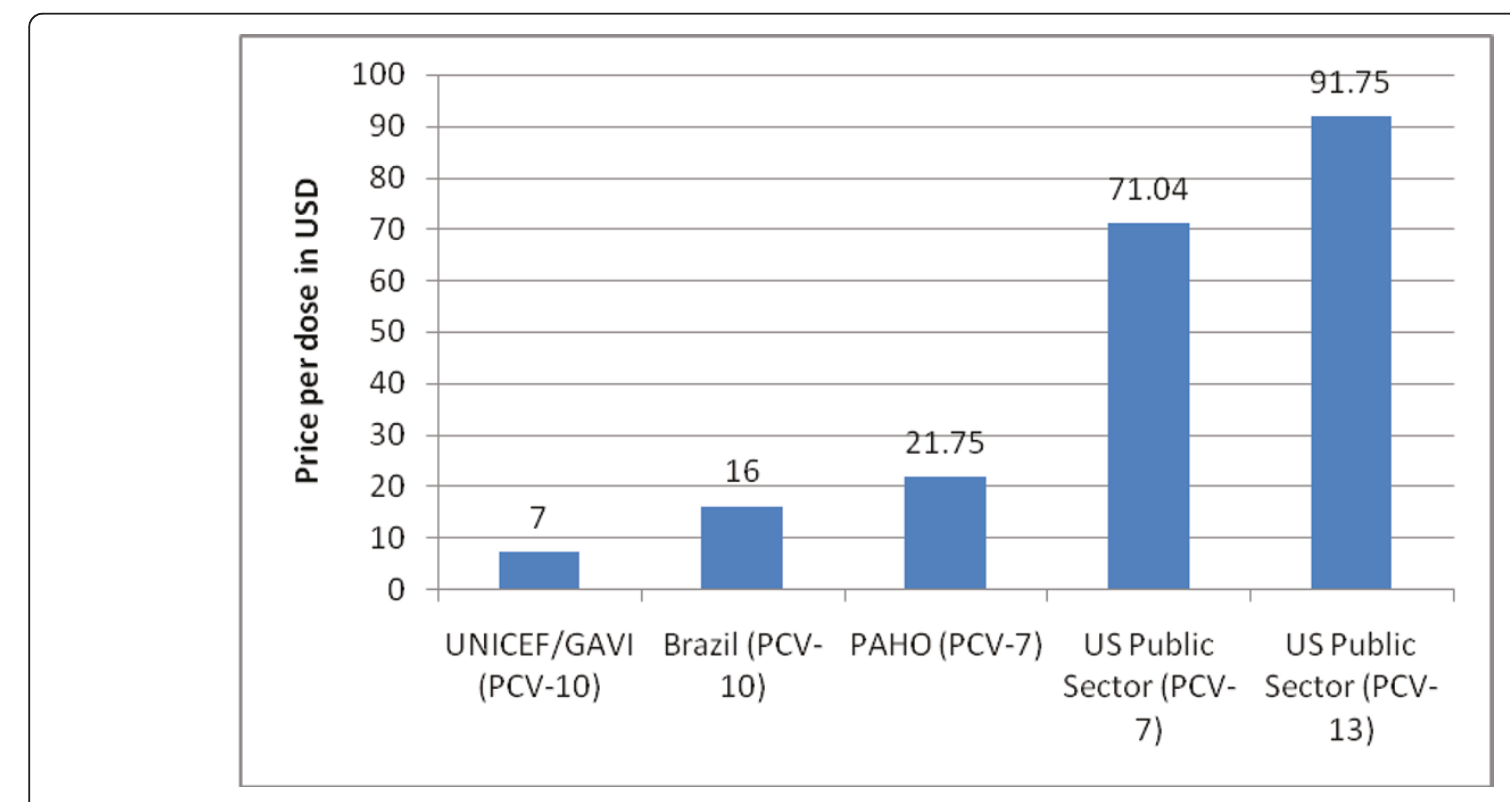

Figure 4 Pneumococcal conjugate vaccine tiered prices. 
place ensuring that poorer countries get the lowest possible prices. Under the AMC/GAVI agreement, the price of the pneumococcal vaccine is fixed at $\$ 7$, then $\$ 3.50$ for the next 10 years, but the production cost has been estimated at $\$ 1-3 /$ dose [39], suggesting that prices would have fallen further over time in a competitive market. These price differences may be particularly important for LMICs that will become ineligible for GAVI funding in the coming years, and will therefore need to pay for vaccines from national budgets. Second, this case underscores the difficulty in determining what is a "fair" price for middle-income countries. Finally, the Brazil-GSK deal suggests that, while large countries with domestic manufacturing capacity may be able to negotiate acceptable prices and technology transfer agreements, for smaller countries without production capacity, the practice of negotiating prices country by country may be less favorable.

In summary, when synthesizing the past decade's experience with tiered pricing in HIV/AIDS, malaria, tuberculosis, visceral leishmaniasis and pneumococcal vaccines, we found that when markets were sizeable and multiple sources of production were available, tiered pricing performed poorly compared to competitive production in generating reliable and sustained price reductions. We also found that in special cases, particularly when markets were small, highly uncertain, where production capacity was limited, or there was a time delay to overcoming barriers to competition, tiered pricing likely contributed to improved access in the short term. However, beyond price, we also found that tiered pricing raised further issues requiring consideration as discussed in the following sections.

\section{Tiering and Pricing: Variations vs Principles \\ Differential and Arbitrary Tiering Among Countries}

Current tiered pricing policies take various approaches to country classification. Drug companies rarely provide an explicit rationale for why they offer their lowest prices to some countries, somewhat higher prices for others, and for still others negotiate prices on a case-bycase basis. Some companies use World Bank income classifications based on per capita GNI (low, lower-middle, upper-middle, and high-income), while others use development indicators, such as the UN-designated LDCs or the UN Development Programme's Human Development Index. Finally, some companies offer their lowest prices, such as for ARVs, to all sub-Saharan African countries, regardless of income or LDC status, presumably because of the disproportionately high burden of HIV in the region.

For example, for ARV pricing, Bristol-Myers Squibb includes 57 developing countries in its Category 1, primarily low-income and African countries, but places southern African countries in Category 2. Southern Africa, however, has the highest HIV-prevalence rates in the world. The impact of this categorization is that Bristol-Myers Squibb prices its important second-line drug atazanavir 25\% higher at \$547 in southern Africa, compared with $\$ 412$ in other countries where HIV prevalence is lower and, in a few cases, income is higher [17].

Thus, tiered pricing policies are not necessarily logical nor correlated with need or ability to pay, though that is the purported objective. How companies decide to put countries into different pricing tiers is not always clear, nor is there consensus on the criteria by which to do so.

\section{Intra-Country Price Differences}

Within-country market segmentation In some cases, within-country tiered pricing has been proposed and/or implemented, and evidence suggests internal market segmentation may be feasible. For example, Yadav has presented evidence from the malaria drug market in sub-Saharan Africa suggesting that price differences can be maintained between "premium" and "non-premium" private sector distribution channels, through branding and other marketing strategies [40]. However, the distributional effects of particular segmentation policies should also be examined.

Perhaps the most common approach is to segment the public and private sectors, with lower prices for government-provided medicines. However, such a simple division may not be equitable, since countries vary widely in the extent to which a population purchases medicines in the public or private sector, and private sector customers are not necessarily wealthier than those who rely on the public sector. For example, over $70 \%$ of the TB drug market in India and the Philippines is in the private sector, while in Brazil and South Africa, TB drugs are mostly dispensed via the public sector [41].

In addition, in a study of 36 countries Cameron et al. found the availability of medicines to be higher in the private than public sector, though public sector prices tended to be lower [42]. Although incomes are generally lower in rural areas, public health centers are often sparse, meaning that poor, rural populations may rely on private dispensaries to purchase medicines. Thus, a tiered pricing model that only offers affordable prices to the public sector could exclude a substantial proportion of the poor population in some countries.

Another proposed method to achieve internal market segmentation is to charge higher prices in the insured market, while offering lower prices for all other sectors, including public, private, and non-profit (personal communication, K. Outterson, 2010). If such a policy could feasibly be implemented, and if health insurance coverage were sufficient to pay for the prices of needed medicines, then such a division could lead to more equitable distributional outcomes than a simple public-private 
sector division. However, many developing countries having extremely limited insurance systems with very low coverage.

Within-country inequality A key weakness with pricing medicines according to per capita GNI levels is that many middle-income countries are also characterized by high levels of inequality. South Africa and Brazil, for example, are the $8^{\text {th }}$ and $10^{\text {th }}$ most unequal out of 182 ranked countries in the world (Table 4) [43]. Tiered prices may be within reach for the upper or middle classes in a country, but not for the poor. In a 2002 study of 13 countries, Wong found that medicine prices were higher in countries with higher levels of inequality, but per capita gross domestic product (GDP) had no significant effect on price [44].

\section{Setting Fair Prices: How and Who}

With respect to tiered prices for middle-income countries, there is no norm for what constitutes a "fair" premium on LDC or low-income country prices. In practice, prices may be determined by many factors besides the ability to pay, such as negotiating capacity, market size, and degree of competition.

For example, in 2006, Honduras purchased LPV/r at a price about 6 times that of Brazil, although the two countries' adult HIV prevalence rates are roughly equivalent $(\sim 0.5 \%)$ and Honduras' per capita GNI is only one-fourth that of Brazil's. Brazil's larger market and ability to credibly threaten the use of compulsory licensing were likely to have contributed to the lower prices achieved there [45].

In most high-income markets, governments play a central role in regulating medicine prices, such as through reference pricing, setting reimbursement rates, and price controls. In contrast, smaller countries and those without domestic pharmaceutical industries have much less bargaining power and often face greater difficulty achieving affordable prices in case-by-case price negotiations with companies. Under tiered pricing policies, firms generally set the price and choose which countries will receive which price. In short, tiered

Table 4 Selection of intra-country inequality scores

\begin{tabular}{cccc}
\hline Country & Gini coefficient & Rank & Income category \\
\hline Namibia & 74.3 & $1^{\text {st }}$, most unequal & Upper middle \\
South Africa & 57.8 & $8^{\text {th }}$ & Upper middle \\
Brazil & 57.0 & $10^{\text {th }}$ & Upper middle \\
China & 46.9 & $58^{\text {th }}$ & Lower middle \\
East Timor & 39.5 & $71^{\text {st }}$, median & Lower middle/LDC \\
India & 36.8 & $87^{\text {th }}$ & Lower middle \\
Bangladesh & 33.4 & $124^{\text {th }}$ & Low income/LDC \\
Denmark & 24.7 & $182^{\text {nd }}$, most equal & High income \\
\hline
\end{tabular}

$\mathrm{LDC}=$ least developed country

Source: UNDP 2009 [43] pricing policies give most of the decision-making power to private firms, whose pricing decisions may not necessarily be aligned with the public interest.

Besides ability to pay, a range of factors could facilitate fair price setting, including therapeutic or public health value, drug production costs, total R\&D costs, and public investment in $R \& D$. Lopert et al. proposed setting tiered prices based on pharmacoeconomic principles [46]: setting a fair, objectively calculated price taking into account a product's public health benefit, cost-benefit ratio, availability of alternatives, potential cost savings in other parts of the healthcare system, and degree of public or philanthropic R\&D funding. Such a system could shift the alignment of rewards for innovation closer to public health needs, rather than market profitability. To our knowledge, this approach has not yet been applied in developing countries, but such systems are in place in the UK, Canada, and Australia, where national governments are major purchasers of pharmaceuticals. However, pharmacoeconomic approaches may need to be combined with other measures to achieve equity pricing of important medicines [47].

\section{Summary}

Contrary to the idea that tiered pricing is a "win-win" solution, this review of the evidence and literature suggests key economic and political drawbacks to this policy tool. Currently, there is no straightforward, equitable way to set tiered prices to achieve affordability.

First, tiered pricing does not necessarily result in the lowest sustainable prices, nor does it reliably lead to price reductions over time. In comparison, when markets are sufficiently large and multiple sources of production exist, robust competition has consistently proven across different therapeutic areas to result in lower prices. Second, no clear international norm has been established for setting price tiers, nor is there a simple or satisfactory way to allocate payment for $R \& D$ costs across various developing countries. The distributional nature of the question is fundamentally political rather than technical. Finally, tiered pricing policies give too little decision-making power to governments, which are accountable to their populations under international law for ensuring access to medicines. Rather, tiered pricing leaves this important issue almost entirely in the hands of private companies over which populations have few means to demand accountability.

In special cases however, such as when market volumes are very small or highly uncertain (eg, drugresistant TB) and/or multisource production capacity is lacking (eg, newer products like the pneumococcal vaccine), tiered pricing may offer the only practical shortterm option to increase access to a product. In such cases, tiered pricing should be implemented in the short 
term, while simultaneous steps are taken to improve affordability and availability over the longer term. Where markets are small and economies of scale make a single producer the most efficient solution, credible means to verify "at-cost" or "cost-plus" supply commitments are needed. In cases where global production capacity is limited, policies should encourage rapid technology transfer to transition as quickly as possible to a competitive market. In general, competition should be the default option for improving the affordability of medicines in developing countries. Increasingly, ensuring such competition will require addressing the challenges posed by more widespread patenting of medicines in developing countries [48]. These conclusions have particular policy relevance for major purchasers of medicines, who have the power to shape markets for these products; such actors include governments of large developing countries and global health initiatives such as GAVI, the Global Fund (which has a Market Dynamics Committee), UNITAID (which is centrallyfocused on market dynamics), and the United Nations Childrens Fund (UNICEF).

If not tiered pricing, then what? Given the many difficulties around setting tiered prices, pricing through competition offers clear advantages. Making competitively produced medicines available in all developing countries would minimize the complications of internal market segmentation, since the lowest prices would be available across all sectors. Policies enabling such competition merit further attention. Such policies may include voluntary measures by patent holders such as widespread voluntary licensing, participating in the UNITAID-supported Medicines Patent Pool [49], non-assert declarations, or decisions not to apply for or maintain patents in developing countries. They may also include policies adopted by governments, such as regular compulsory licensing where patents exist, or limiting patent grants through strict patentability criteria and procedures to facilitate pre- and post-grant oppositions on patent applications.

However, such a system will only work in the long term if markets are large enough and alternate solutions for financing $R \& D$ can be implemented. The current system relies on the ability of producers to recoup R\&D investments by charging a significant market premium above production costs. If alternate models could be implemented that "de-link" medicine prices from R\&D costs, many of the thorny economic, logistical, and political problems raised by tiered pricing could be averted. Proposals that de-link prices from $R \& D$ include push funding, prizes [50,51], patent pools [52], and patent buy-outs [53]. Furthermore, R\&D policies could also incentivize developers to take production costs into account throughout the development process, making affordability of the end product more feasible. Some public-private product development partnerships (PDPs) targeting resourcepoor settings already consider production costs when deciding which compounds to pursue.

A political process is required to determine how countries should contribute to $R \& D$ financing as a global public good. The debate on this issue advanced through the 2year WHO Intergovernmental Working Group on Public Health, Innovation and Intellectual Property (IGWG, 2006-2008) process, which resulted in the Global Strategy and Plan of Action on Public Health, Innovation and Intellectual Property (GSPoA). It is too early to draw conclusions, as implementation of the GSPoA is just beginning and work continues on key questions regarding $R \& D$ financing. Nevertheless, the international community is clearly seeking policy solutions that extend beyond the limited benefits of tiered pricing, in order to institute systemic change that will improve access to medicines for all.

\section{Acknowledgements}

We would like to thank the following individuals for comments, data, critiques, and useful discussions through the development of this article: Brook Baker, Daniel Berman, Pascale Boulet, Pierre Chirac, Charles Clift, Karen Day, Margriet den Boer, Laurent Gadot, Janice Lee, Kevin Outterson, Bernard Pécoul, Ellen 't Hoen, Prashant Yadav, and Oliver Yun. All errors and omissions remain our own.

\section{Author details}

${ }^{1}$ Harvard Kennedy School and School of Public Health, Boston, USA. ${ }^{2}$ Médecins Sans Frontières, Campaign for Access to Essential Medicines, Geneva, Switzerland

\section{Authors' contributions}

SM drafted the manuscript and participated in conception, design, and analysis. EJ, MC, and TVSA participated in conception, design, analysis, and interpretation, and revised critically the manuscript. All authors read and approved the final manuscript.

\section{Competing interests}

The authors declare that they have no competing interests.

Received: 24 June 2011 Accepted: 12 October 2011

Published: 12 October 2011

\section{References}

1. World Bank: How we classify countries. 2009 [http://data.worldbank.org/ about/country-classifications].

2. Danzon PM, Towse A: Differential pricing for pharmaceuticals: Reconciling access, R\&D and patents. AEl-Brookings Joint Center Working Paper No. 03-7 2003 [http://ssrn.com/abstract=422821].

3. Moon S: Medicines as global public goods: The governance of technological innovation in the new era of global health. Glob Health Gov 2009, 2:1-23[http://www.ghgj.org/moon2.2medecinespublicgood.htm].

4. Sukkar E: UK kick-starts differential pricing debate for developing world. Scrip World News 2009, 28-29.

5. European Union: Essential Medicines for Developing Countries (HIV/AIDS, Tuberculosis and Malaria). 2006 [http://europa.eu/legislation_summaries/ development/sectoral_development_policies/l21166_en.htm].

6. Mackay B: Summary report of Industry Government Forum on Access to Medicines (IGFAM). London: DFID Health Resources Center. Meeting report; 2009.

7. Witty A: Big pharma as a catalyst for change. February 13, 2009 Speech to Harvard Medical School. 2009 [http://www.gsk.com/media/downloads/ Witty-Harvard-Speech-Summary.pdf]. 
8. Yadav P: Differential pricing of pharmaceuticals: Review of current knowledge, new findings and ideas for action. A study conducted for the UK Department for International Development (DFID). Zaragoza, Spain: MITZaragoza International Logistics Program 2010 [http://www.dfid.gov.uk/ Documents/publications1/prd/diff-pcing-pharma.pdf].

9. Plahte J: Tiered pricing of vaccines: A win-win-win situation, not a subsidy. Lancet Infect Dis 2005, 5:58-63.

10. Ramsey FP: A contribution to the theory of taxation. Econ J 1927, 37:47-61.

11. WHO: The world drug situation. Geneva; 1988.

12. Xu K, Evans D, Kawabata K, Zeramdini R, Klavus J, Murray CJ: Household catastrophic health expenditure: a multicountry analysis. Lancet 2003, 362:111-117

13. WHO: Commission on Intellectual Property Rights, Innovation and Public Health (CIPIH). Public Health, Innovation and Intellectual Property Rights Geneva; 2006.

14. Niëns $L$, Brouwer $W$ : Better measures of affordability required. Lancet 2009, 373:1081.

15. Niëns LM, Cameron A, Van de Poel E, Ewen M, Brouwer WBF, Laing R: Quantifying the impoverishing effects of purchasing medicines: A crosscountry comparison of the affordability of medicines in the developing world. PLOS Med 2010, 7:e1000333.

16. Waning B, Kaplan W, King AC, Lawrence DA, Leufkens HG, Fox MP: Global strategies to reduce the price of antiretroviral medicines. Evidence from transactional databases. Bull World Health Organ 2009, 87:520-528.

17. Médecins Sans Frontières (MSF), Campaign for Access to Essential Medicines: Untangling the web of antiretroviral price reductions (online edition)., 142011 [http://utw.msfaccess.org/].

18. Frank RG, Salkever DS: Generic entry and the pricing of pharmaceuticals. J Econ Manag Strategy 1997, 6:75-90.

19. Baker BK, Ombaka E: The danger of in-kind drug donations to the Global Fund. Lancet 2009, 373:1218-1221.

20. Waning B, Kyle M, Diedrichsen E, Soucy L, Hochstadt J, Bärnighausen T, Moon S: Intervening in global markets to improve access to HIV/AIDS treatment: An analysis of international policies and the dynamics of global antiretroviral medicines markets. Global Health 2010, 6:9.

21. WHO: Rapid advice: Antiretroviral therapy for HIV infection in adults and adolescents. Geneva; 2009.

22. WHO: Towards universal access: Scaling up priority HIV/AIDS interventions in the health sector. Geneva; 2009.

23. Perez-Casas C, Mace C, Berman D, Double J: Untangling the web of antiretroviral price reductions. $1^{\text {st }}$ ed. Médecins Sans Frontières, Campaign for Access to Essential Medicines 2001 [http://utw.msfaccess.org/downloads/ 311].

24. Médecins Sans Frontières (MSF), Campaign for Access to Essential Medicines: Untangling the web of antiretroviral price reductions., 82005 [http://utw.msfaccess.org/downloads/161].

25. Waning B, Diedrichsen E, Moon S: Market shift towards heat-stable lopinavir/ritonavir demonstrates the need for improved formulations for second-line treatment of HIV/AIDS in low- and middle-income countries. Poster Presentation, XVIII International AIDS Conference Vienna; 2010.

26. Carreyrou J: New regimen: Inside Abbott's tactics to protect AIDS drug. Wall St J 2007

27. Safeway Inc., et al. v. Abbott Laboratories: Hon. C. Wilken, California Northern District Court, case number 4:2007cv05470. 2007 [http:// dockets.justia.com/docket/california/candce/4:2007cv05470/197311/].

28. Law360: 9th Circ. rejects rehearing on Norvir antitrust deal. New York; 2009 [http://www.law360.com/articles/117786]

29. $\mathrm{WHO}: \mathrm{WHO}$ and Novartis join forces to combat drug resistant malaria. 2001.

30. Moon S, Pérez Casas C, Kindermans J, de Smet M, von Schoen-Angerer T: Focusing on quality patient care in the new global subsidy for malaria medicines. PLoS Med 2009, 6:e1000106.

31. Médecins Sans Frontières (MSF) and International Union Against Tuberculosis and Lung Disease (IUATLD): DR-TB drugs under the microscope: Sources and prices for drug-resistant tuberculosis medicines. 2011 [http://www.msfaccess.org/sites/default/files/MSF_assets/ TB/Docs/TB_report_UndertheMicro_ENG_2011.pdf].

32. British National Formulary. , 602010.

33. WHO: Guidelines for the programmatic management of drug-resistant tuberculosis: Emergency update. Geneva; 2008.
34. WHO: Towards universal access to diagnosis and treatment of multidrug-resistant and extensively drug-resistant tuberculosis by 2015 . Geneva; 2011

35. Bern C, Adler-Moore J, Berenguer J, Boelaert M, den Boer M, Davidson RN, Figueras C, Gradoni L, Kafetzis DA, Ritmeijer K, Rosenthal E, Royce C, Russo R, Sundar S, Alvar J: Liposomal amphotericin B for the treatment of visceral leishmaniasis. Clin Infect Dis 2006, 43:917-924

36. GAVI Alliance: Advance Market Commitment for Pneumococcal Vaccines: Annual Report 12 June 2009-31 March 2010. Geneva; 2010.

37. GAVI Alliance: Who can apply. 2011 [http://www.gavialliance.org/support/ who/index.php].

38. Jack A: GSK signs lifetime deal with Brazil for pneumococcal vaccine. Financ Times 2009.

39. Wilson P: Giving developing countries the best shot: An overview of vaccine access and R\&D. Oxfam International and MSF Campaign for Access to Essential Medicines. Geneva: 2010.

40. Yadav P: Differential pricing: The interface of economics and supply chains. London; 2009, Presented at DFID Industry-Government Forum on Access to Medicines.

41. TB Alliance: Pathway to Patients: Charting the Dynamics of the Global TB Drug Market. Global Alliance for TB Drug Development, New York 2007 [http://www.tballiance.org/aaa/groundwork.php].

42. Cameron A, Ewen M, Ross-Degnan D, Ball D, Laing R: Medicine prices, availability, and affordability in 36 developing and middle-income countries: A secondary analysis. Lancet 2009, 373:240-249.

43. United Nations Development Programme (UNDP): Human Development Report 2009: Overcoming Barriers: Human Mobility and Development. New York; 2009 [http://hdrstats.undp.org/en/indicators/161.html].

44. Wong EV: Inequality and pharmaceutical drug prices: An empirical exercise. Discussion Papers in Economics. Center for Economic Analysis, Department of Economics, University of Colorado, Boulder, CO. Working Paper 02-19

45. Ford N, Wilson D, Chaves GC, Lotrowska M, Kijtiwatchakul K: Sustaining access to antiretroviral therapy in the less-developed world: Lessons from Brazil and Thailand. AIDS 2007, 21(Suppl 4):S21-S29.

46. Lopert $\mathrm{R}$, Lang DL, Hill SR, Henry DA: Differential pricing of drugs: A role for cost-effectiveness analysis? Lancet 2002, 359:2105-2107.

47. Organisation for Economic Cooperation and Development (OECD): Pharmaceutical Pricing Policies in a Global Market. OECD Health Policy Studies 2008.

48. 't Hoen E: The global politics of pharmaceutical monopoly power: Drug patents, access, innovation, and the application of the WTO Doha Declaration on TRIPS and public health. Diemen, the Netherlands: AMB Press; 2009.

49. Medicines Patent Pool. Geneva; 2010 [http://www.medicinespatentpool. org].

50. Hubbard T, Love J: A new trade framework for global healthcare R\&D. PLoS Biol 2004, 2:e52

51. Finkelstein SN, Temin P: Reasonable Rx: Solving the Drug Price Crisis. Upper Saddle River, NJ: FT Press/Pearson Education 2008

52. Bermudez J, 't Hoen E: The UNITAID Patent Pool Initiative: Bringing patents together for the common good. Open AIDS J 2010, 4:37-40.

53. Outterson K: Patent buy-outs for global disease innovations for low- and middle-income countries. Am J Law Med 2006, 32:159-173.

54. Global Fund to Fight AIDS, Tuberculosis and Malaria: Global Fund Price and Quality Reporting. 2010 [http://pqr.theglobalfund.org].

55. Management Sciences for Health: International Drug Price Indicator Guide. Capreomycin. 2009 [http://erc.msh.org/dmpguide/resultsdetail.cfm? language $=$ english \&code $=C A P R 1 \&$ s_year $=2009 \&$ year $=2009 \& \mathrm{str}=1 \%$ 20g\&desc $=$ Capreomycin\&pack=new\&frm $=$ VIAL\&rte=INJ\&class_code2=06.2.4. \&supplement=\&class_name=(06.2.4.)Antituberculosis\%20medicines\%3Cbr\%3E].

56. Management Sciences for Health: International Drug Price Indicator Guide. Cycloserine. 2009 [http://erc.msh.org/dmpguide/resultsdetail.cfm? language $=$ english \&code $=C Y C S 250 T \& s \_y e a r=2009 \&$ year $=2009 \& s t r=250 \%$ 20mg\&desc $=$ Cycloserine\&pack $=$ new\&frm $=T A B-$

CAP\&rte $=$ PO\&class_code2 $=06.2 .4$.\&supplement $=\&$ class_name $=(06.2 .4$. $)$ Antituberculosis\%20medicines\%3Cbr\%3E].

doi:10.1186/1744-8603-7-39

Cite this article as: Moon et al:: A win-win solution?: A critical analysis of tiered pricing to improve access to medicines in developing countries. Globalization and Health 2011 7:39. 